\title{
RESPONSE OF ANTIOXIDATIVE SYSTEM OF BRASSICA JUNCEA (L.) CZERN. TO TERMINAL HEAT STRESS
}

\author{
Narender Mohan ${ }^{1}$, Nisha Kumari ${ }^{1}{ }^{*}$, Minakshi Jattan, \\ Ram Avtar, Babita Rani ${ }^{1}$ AND SuShIL ${ }^{2}$ \\ Oilseed Section, Department of Genetics and Plant Breeding, \\ CCS Haryana Agricultural University, Hisar-125 004, India
}

Keywords: Antioxidative system, Indian mustard, Terminal heat stress

\begin{abstract}
A differential response to terminal heat stress was observed on enzymatic and non-enzymatic components of antioxidant system of two thermo-tolerant genotypes viz., RGN-368 \& RH-1566 and two thermo-sensitive genotypes viz., RH-1134 \& RH-0749 in leaves of Indian mustard. The antioxidative enzymes viz., superoxide dismutase, peroxidase, catalase, ascorbate peroxidase and glutathione reductase showed higher activity in leaves of two thermo-tolerant genotypes as compared to thermo-sensitive. Terminal heat stress resulted in concomitant increase in non-enzymatic components like carotenoids, ascorbic acid and proline in all the genotypes but maximum increase was observed in thermo-tolerant genotypes. A remarkable accumulation was observed in oxidative stress indicators i.e., malondialdehyde, hydrogen peroxide and electrolyte leakage in all the genotypes, whereas, significant increase was observed in thermo-sensitive genotypes as compared to thermo-tolerant. It is inferred that leaves of thermo-tolerant genotypes tend to attain greater capacity to perform reaction of antioxidative pathway under the condition of terminal heat stress to combat thermo-induced oxidative stress.
\end{abstract}

Indian mustard (Brassica juncea (L.) Czern. \& Coss. belonging to Brassicaceae is the second largest oilseed crop in India after soybean. It accounts for nearly $30 \%$ of the total oilseeds and $27 \%$ to edible oil pool of the country. High temperature, specially terminal heat stress in late sown crop, is the second most important stress next to drought. It has devastating effects on plant growth and metabolism (Asthir 2015). Variability in temperature affects the grain and seed yield of annual crops. Generally plants respond to heat stress through developmental, biochemical and physiological changes and the type of observed responses depends on several factors such as stress intensity, stress duration and genotype (Moradshahi et al. 2004). This stress leads to generation of reactive oxygen species (ROS) and further tissue dehydration.

Plants being sessile are unable to escape the stress as such, but try to maintain cellular equilibrium by mechanisms of avoidance and tolerance which includes early maturation, alteration of membrane lipids composition, expression of stress proteins and other enzymatic and nonenzymatic mechanisms to scavenge the rapidly evolving ROS (Esfandiari et al. 2007). So the objective of this study was to evaluate the response of thermo-tolerant and thermo-sensitive genotypes of $B$. juncea to terminal heat stress in terms of antioxidants.

The four genotypes of B. juncea viz., RGN-368, RH-1566, RH-1134 and RH-0749 were sown in research area of Oilseeds Section, Department of Genetics and Plant Breeding in RBD on two dates of sowing i.e. October 13 (timely) and November 15 (late) in three replications. Leaves of $B$. juncea genotypes after 90 days of sowing were used for further studies.

*Author for correspondence: <nishaahlawat211@gmail.com>. 'Department of Biochemistry, CCS Haryana Agricultural University, Hisar-125 004, India. ${ }^{2}$ Department of Chemistry, CCS Haryana Agricultural University, Hisar-125 004, India. 
The MDA was estimated according to the method of Heath and Packer (1968). The $\mathrm{H}_{2} \mathrm{O}_{2}$ was estimated by the method of Sinha (1972). The relative intactness of plasma membrane was measured as the leakage percentage of electrolytes, as described by Gong et al. (1998). The SOD activity was determined by quantifying the ability of the enzyme to inhibit the photochemical reduction of nitro blue tetrazolium (NBT) to formazan (Beauchamp and Fridovich 1971). One unit of SOD activity is the amount of enzyme which causes 50 per cent inhibition of the photochemical reaction. One unit of POX activity is equivalent to $\mu$ mole of $\mathrm{H}_{2} \mathrm{O}_{2}$ oxidized per minute (Shannon et al. 1966). One unit of catalase activity is the amount of enzyme required to consume one $\mu$ mole $\mathrm{H}_{2} \mathrm{O}_{2}$ per minute under assay conditions (Sinha 1972). One unit of APX activity is the amount of enzyme utilized to oxidize one $\mu$ mole of ascorbic acid per minute (Nakano and Asada 1981). One unit of glutathione reductase is defined as $100 \mu$ mole of NADPH oxidized per minute (Halliwell and Foyer 1978).
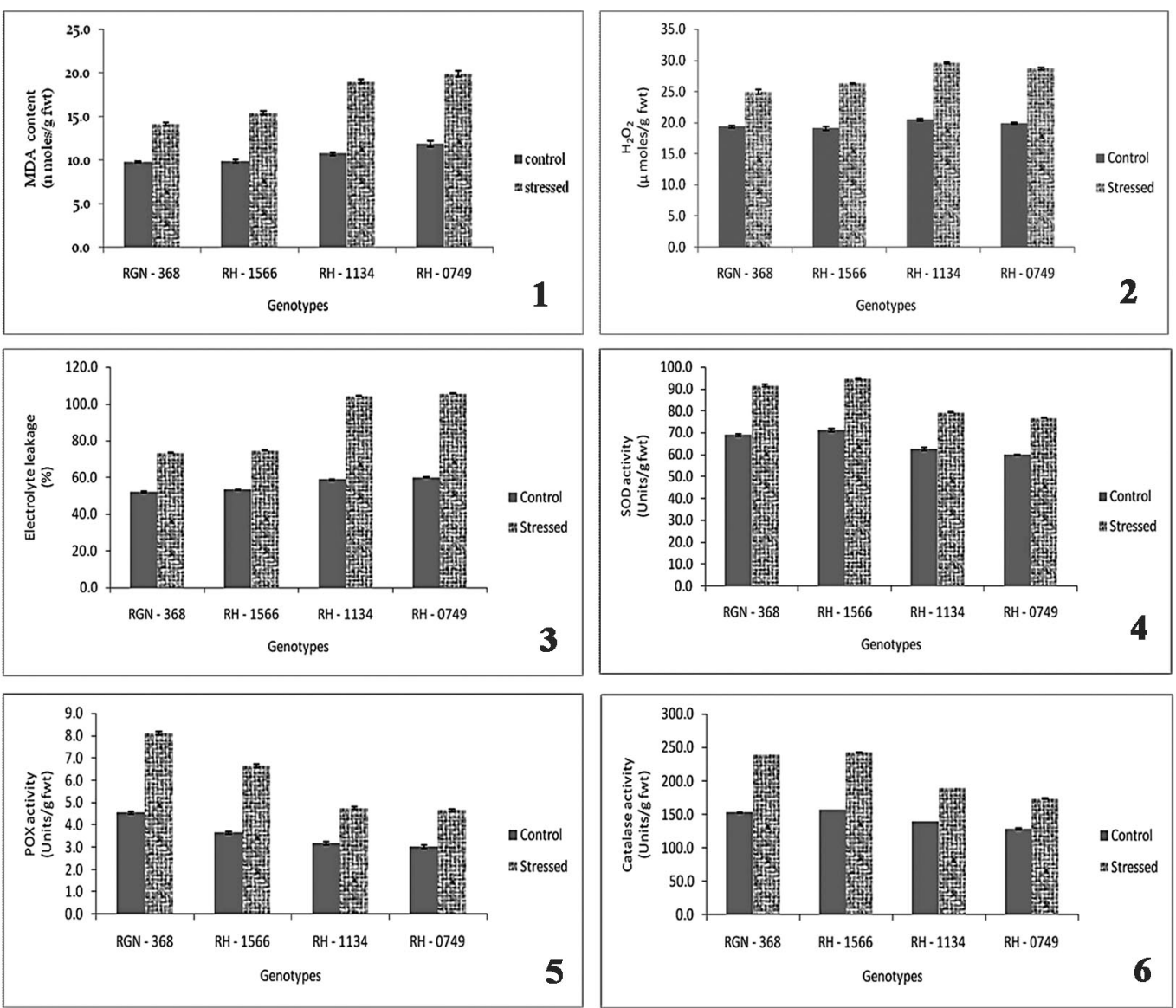

Figs 1-6: 1. Effect of terminal heat stress on MDA content in Indian mustard. $\mathrm{CD}$ at $5 \%$ : Genotype $=0.5$ treatment $=0.353$ genotype $\times$ treatment $=0.707$. 2. Effect of terminal heat stress on $\mathrm{H}_{2} \mathrm{O}_{2}$ content in Indian mustard. $\mathrm{CD}$ at $5 \%$ : Genotype $=0.448$ treatment $=0.317$ genotype $\times$ treatment $=0.634 .3$. Effect of terminal heat stress on electrolyte leakage in Indian mustard. $\mathrm{CD}$ at $5 \%$ : Genotype $=0.594$ treatment $=0.42$ genotype $\times$ treatment $=0.84 .4$. Effect of terminal heat stress on SOD activity in Indian mustard. CD at 5\%: Genotype $=0.888$ treatment $=0.628$ genotype $\times$ treatment $=1.256 .5$. Effect of terminal heat stress on POX activity in Indian mustard. CD at $5 \%$ : Genotype $=0.13$ treatment $=0.092$ genotype $\times$ treatment $=0.184$. 6. Effect of terminal heat stress on CAT activity in Indian mustard. $\mathrm{CD}$ at $5 \%$ : Genotype $=1.178$ treatment $=0.833$ genotype $\times$ treatment $=1.666$. 
Ascorbic acid content was estimated by the method of Roe (1964). The carotenoids extracted in the DMSO were estimated by the method of Hiscox and Israelstam (1979). For proline estimation, standard method of Bates et al. (1973) was used. The data were analyzed statistically using CRD at 5\% level of significance using OPSTAT software (CCS HAU, Hisar).

Malondialdehyde, $\mathrm{H}_{2} \mathrm{O}_{2}$ and electrolyte leakage are considered as indicators of degree of oxidative damage. Effect of THS on the MDA, $\mathrm{H}_{2} \mathrm{O}_{2}$ content and electrolyte leakage showed a significant increase in all genotypes under stress condition (Figs 1 - 3). However, this increment for MDA, $\mathrm{H}_{2} \mathrm{O}_{2}$ content and electrolyte leakage was more in thermo-sensitive genotypes i.e. $\mathrm{RH}-$ 1134 (77.16, 44.71 and 77.65\%, respectively) and RH-0749 (67.88, 44.36 and 76.09\%, respectively). These results are in agreement with those reported by Kumar et al. (2013), Rani et al. (2016) and Kavita and Pandey (2017) in Indian mustard under heat stress.
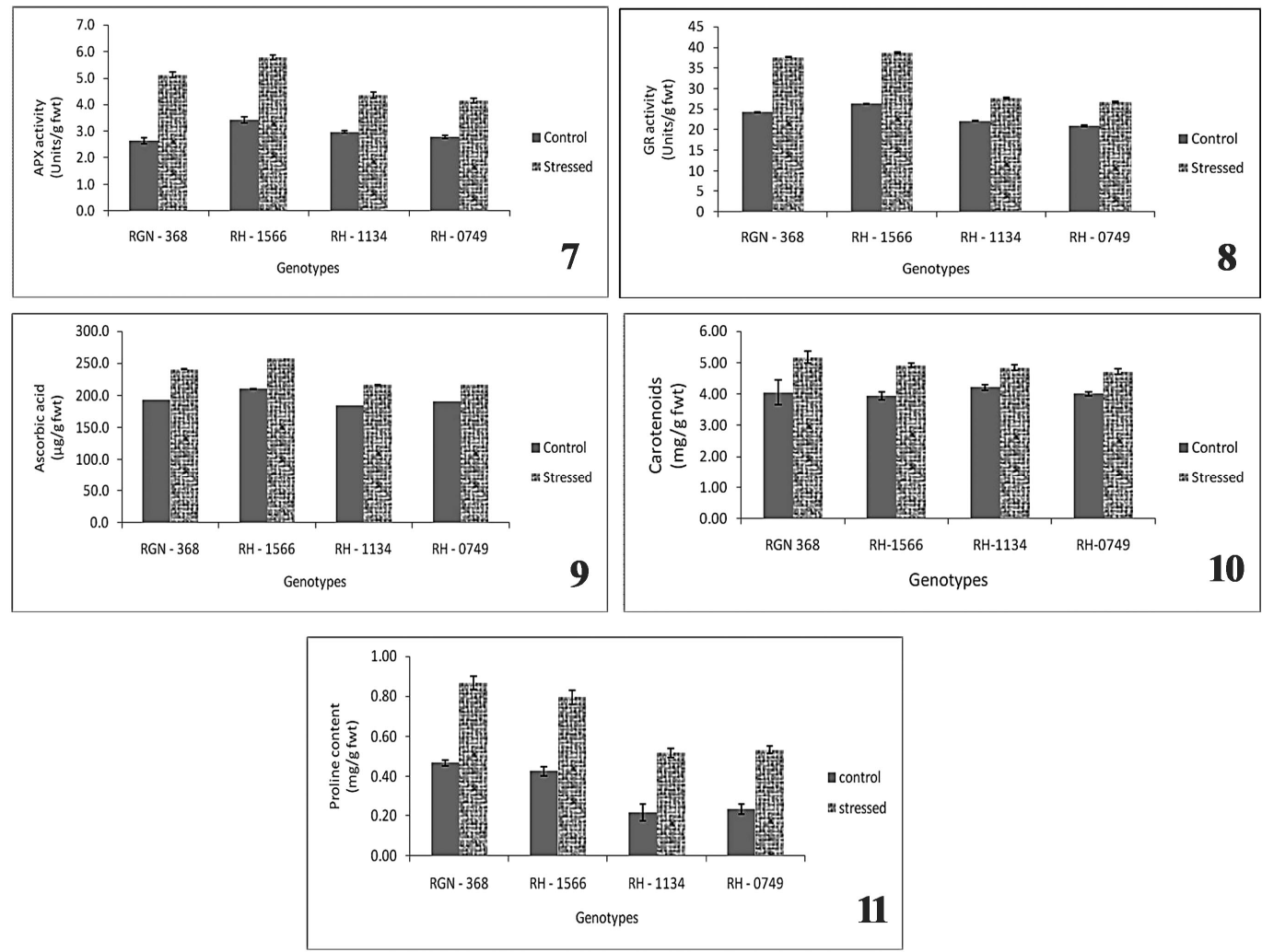

Figs 7-11: 7. Effect of terminal heat stress on APX activity in Indian mustard. CD at $5 \%$ : Genotype $=0.199$ treatment $=$ 0.141 genotype $\times$ treatment $=0.282 .8$. Effect of THS on GR activity in Indian mustard. CD at 5\%: Genotype $=0.303$ treatment $=0.214$ genotype $\times$ treatment $=0.428$. 9. Effect of terminal heat stress on ascorbic acid in Indian mustard. $\mathrm{CD}$ at $5 \%$ : Genotype $=0.715$ treatment $=0.506$ genotype $\times$ treatment $=1.011 .10$. Effect of terminal heat stress on carotenoids in Indian mustard. CD at 5\%: Genotype $=$ N.S treatment $=0.257$ genotype $\times$ treatment $=$ N.S. 11. Effect of terminal heat stress on proline content in Indian mustard. $\mathrm{CD}$ at $5 \%$ : Genotype $=0.058$ treatment $=0.041$ genotype $\times$ treatment $=0.082$.

The activity of antioxidative enzymes i.e. SOD, POX, CAT, APX and GR increased significantly in all the genotypes under late sown condition. However, the maximum per cent increase for all these enzymes was observed in thermo-tolerant genotypes as compared to thermo- 
sensitive (Figs 4 - 8). Higher activity of these enzymes under THS in tolerant genotypes might be responsible for providing tolerance (Kumar et al. 2013, Rani et al. 2016).

All the genotypes showed significant increase in ascorbic acid, carotenoid and proline content with a higher increase seen in thermo-tolerant genotypes as compared to thermo-sensitive (Figs 9-11). This higher increase in thermo-tolerant genotypes might be an adaptive advantage to cope with terminal heat stress. These results are in conformity with Kumar et al. (2013), Rani et al. (2016) and Kumar et al. (2018) in Indian mustard under heat stress.

From the results it may be concluded that under terminal heat stress significant increase in antioxidative enzymes and metabolites in thermo-tolerant genotypes might be responsible for imparting tolerance. It may be suggested that the sensitive genotypes can be accorded by exploiting the activity of antioxidative enzymes through genetic engineering.

\section{References}

Asthir B 2015. Protective mechanisms of heat tolerance in crop plants. J. Plant Interact. 10(1): 202-210.

Bates L, Waldren RP, and Teare JD 1973. Rapid determination of free proline for water stress studies. Plant Soil 39: 205-207.

Beauchamp I and Fridovich I 1971. Superoxide dismutase: Improved assays and an assay applicable to acrylamide gels. Anal. Biochem. 44: 276-287.

Esfandiari E, Shekari F and Esfandiari M 2007. The effect of salt stress on antioxidant enzymes' activity and lipid peroxidation on the wheat seedling. Not. Bot. Horti. Agrobot. Cluj-Napoca. 35(1): 48-56.

Gong M, Chen SN, Song YQ and Li ZG 1998. Effect of calcium and calmodulin an intrinsic heat tolerance in relation to antioxidant system in maize seedlings. Aust. J. Plant Physiol. 24: 371-379.

Halliwell B and Foyer CH 1978. Properties and physiological functions of a glutathione reductase purified from spinach leaves by affinity chromatography. Planta 139: 9-17.

Heath RL and Packer L 1968. Photoperoxidation in isolated chloroplasts. I. Kinetics and stoichiometry of fatty acid peroxidation. Arch. Biochem. Biophys. 125: 189-198.

Hiscox JD and Israelstam GF 1979. A method for the extraction of chlorophyll from leaf tissue without maceration. Can. J. Bot. 57: 1332-1334.

Kavita and Pandey A 2017. Physiological attributes for screening of Indian mustard (Brassica juncea Czern. and Coss) genotypes during terminal heat stress. Int. J. Curr. Microbiol. App. Sci. 6: 2908-2913.

Kumar A, Kumar M, Gill P, Dharamvir and Kumar N 2018. Physiological and Biochemical Responses of Indian mustard (Brassica juncea L.) genotypes to different sowing dates. Int. J. Curr. Microbiol. App. Sci. 7(12): 2794-2801.

Kumar S, Sairam RK and Prabhu KV 2013. Physiological traits for high temperature stress tolerance in Brassica juncea. Indian J. Plant Physiol. 18: 89-93.

Moradshahi A, Eskandari BS and Kholdebarin B 2004. Some physiological responses of canola (Brassica napus L.). Iran. J. Sci. Technol. 28: 43-50.

Nakano Y and Asada K 1981. Hydrogen peroxide is scavenged by ascorbate-specific peroxidase in spinach chloroplasts. Plant Cell Physiol. 22(5): 867-880.

Rani B, Kumari N, Pooja, Jain V, Dhawan K, Monika, Avtar R, Kumar A and Sheoran P 2016. Antioxidative system as influenced by high temperature stress in Brassica juncea (L) Czern. \& Coss. Curr. Trends Biotechnol. Pharm. 10(2): 118-125.

Roe JH 1964. Chemical determination of ascorbic dehydroascorbic and diketogluconic acids. In: Biochem. Anal. 1.: Met. (eds.) D. Glick Interscience, New York. 115-139.

Shannon LM, Key E and Law JY 1966. Peroxidase isoenzymes from horse reddish roots: Isolation and physical properties. J. Bio. Chem. 241: 2166-2172.

Sinha AK 1972. Calorimetric assay of catalase. Anal. Biochem. 47: 389-395. 